\title{
Green marketing: esfuerzos por el cuidado y la preservación del medio ambiente con negocios sostenibles*
}

\author{
Mauricio Duque** \\ Laura Mejía*** \\ Johanna Nieto****

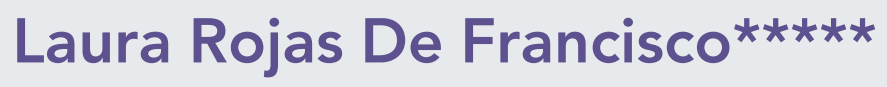

Fecha de recibido: 19 de julio de 2021

Fecha de aprobado: 2 de noviembre de 2021

* El presente artículo es producto de la investigación de trabajo de grado para obtener la maestría en Marketing de la universidad EAFIT con el "Estudio orientador para el Green Marketing como pilar en la estrategia competitiva de las empresas".

** Docente investigador en la Institución Universitaria (EAM) y consultor de Marketing. Especialista y magíster en Mercadeo de la universidad EAFIT, Medellín, Colombia. Máster en Neuromarketing de la Universidad Rey Juan Carlos en Madrid, España. Con experiencia en ventas y consultoría de marketing holístico con enfoque digital. Participó en el grupo de investigación de Administración Financiera de la Universidad del Quindío. Ha publicado en la revista digital de Inesem Business School sobre Neuromarketing. Correo electrónico: ymduquec@eafit.edu.co ORCID: https://orcid.org/0000-0001-6958-5797

*** Business development manager. Especialista y magíster en Mercadeo de la universidad EAFIT, Medellín, Colombia. Representante de ventas de la multinacional Smith + Nephew. Docente en prácticas asistenciales con estudiantes de Instrumentación Quirúrgica y Asistencial, como coordinadora quirúrgica. Consultora en asesoría y creación de nuevos quirófanos. Correo electrónico: Ipmejiaj@eafit.edu.co ORCID: https://orcid.org/0000-0001-8238-6610

**** Especialista y magíster en Mercadeo de la universidad EAFIT, Medellín, Colombia. Consultora de marketing y liderazgo de equipos de alto desempeño, y de marketing digital. Su trayectoria durante 16 años en la Banca Colombiana le han permitido desarrollar habilidades comerciales, visión estratégica y creativa, liderazgo consciente, entre otros. Correo electrónico: ljrendonn@eafit.edu.co ORCID: https://orcid.org/0000-0001-7569-5407

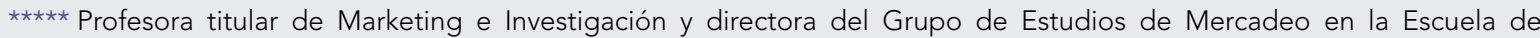
Administración de la Universidad EAFIT, Medellín, Colombia. Doctora en Humanidades Producción y Consumo de Cultura por la Universidad Autónoma de Barcelona (España). Su experiencia se centra en las áreas de análisis del consumo, marketing social, entre otros, además de actividades en la formación de investigadores. Ha publicado en las principales revistas de estudios sobre el ocio, como Journal of Destination Marketing y Management, Journal of Leisure Research, entre otras. Correo electrónico: Irojas3@eafit.edu.co ORCID: https://orcid.org/0000-0002-7250-5599 
Para citar este artículo: Duque, M., Mejía, L., Nieto, J., \& Rojas, L. (2022). Green Marketing: esfuerzos por el cuidado y la preservación del medio ambiente con negocios sostenibles. Revista Universidad \& Empresa, 24(42), 1-36. https://doi.org/10.12804/revistas.urosario.edu.co/ empresa/a.10865

\title{
Resumen
}

Los problemas ambientales han llevado a que los consumidores exijan productos y servicios sostenibles, pero esto ha conducido a que algunas organizaciones hagan prácticas de greenwashing, situación que puede resolverse con conocimiento sobre Green Marketing en las empresas. Esta investigación mixta busca identificar las bases para implementar el green marketing desde la práctica y por ello explora la percepción del tema con organizaciones, expertos en marketing y consumidores en la ciudad de Pereira en Colombia. Los resultados del estudio evidencian el interés por implementar el green marketing en las organizaciones y se contrasta con la percepción de consumidores, aportando, desde bases teóricas, regulatorias y prácticas, aspectos para proponer estrategias y modelos para hacer la transición al green marketing en las organizaciones y hacia las personas.

Palabras Clave: green marketing; sostenibilidad; greenwashing; mercadeo verde; mercadeo ecológico.

\section{Green Marketing: Efforts for Taking Care of and Preserving the Environment with Sustainable Businesses}

\begin{abstract}
Environmental problems have led consumers to demand sustainable products and services, but organizations have turned into greenwashing practices. This situation shows the need to implement green marketing in companies. This mixed research aims to identify the bases for implementing green marketing and explores the perception of subjects related to organizations, marketing experts, and consumers in the city of Pereira, Colombia. The results of this study show the interest in implementing green marketing in organizations that contrasted with the perception of some consumers. At the same time, it provides theoretical, regulatory, and practical bases to propose strategies and models to make the transition to green marketing in organizations and towards people.
\end{abstract}

Keywords: green marketing; sustainability; greenwashing; green marketing; ecological marketing.

\section{Green marketing: esforços para o cuidado e preservação do meio ambiente com negócios sustentáveis}

\section{Resumo}

Os problemas ambientais têm levado os consumidores a exigirem produtos e serviços sustentáveis, mas isso tem levado algumas organizações a fazerem práticas de greenwashing, situação que pode ser resolvida com a difusão de conhecimento sobre green marketing nas empresas. Esta pesquisa mista busca identificar as bases para implementar o marketing verde a partir da prática e, portanto, explora a percepção do assunto com organizações, especialistas em marketing e consumidores na cidade de Pereira, na Colômbia. Os resultados do estudo evidenciam o interesse em implementar o green marketing nas organizações e se contrapõe à percepção dos consumidores, contribuindo a partir de bases teóricas, regulamentares e práticas, aspectos para propor estratégias e modelos para fazer a transição para o green marketing nas organizações e para as pessoas.

Palavras-chave: green marketing; sustentabilidade; greenwashing; marketing verde; marketing ecológico. 


\section{Introducción}

La sostenibilidad, que se ha venido consolidando como una mega tendencia frente a la situación ambiental y de los ecosistemas, requiere del compromiso de gobiernos, empresas, instituciones y personas para generar un impacto positivo en el medio ambiente (Baquero Garzón, 2018) y buscar el equilibrio entre sistema económico ambiental y social (oNU, 2015). Esta tendencia, considerada como la capacidad de satisfacer las necesidades del ser humano sin causar un mal a las futuras generaciones, deber ser hoy un pilar de las organizaciones según apuntan Kotler y Keller (2016).

En ese panorama, el green marketing o marketing verde es una posibilidad para que las empresas desarrollen procesos para generar impacto ambiental positivo, que, además, es la respuesta a una necesidad relacionada con aspectos como la crisis climática, la pobreza, el hambre, la discriminación, y la energía asequible y no contaminante, entre otros, convirtiéndose en una macro tendencia que debe verse a través de procesos enfocados hacia la atención de las expectativas de consumidores que cada vez están más informados.

En este sentido, por ejemplo, la American Marketing Association expone que el green marketing (GM) implica desarrollar nuevos productos y empaques, una forma diferente de distribuirlos y comunicarlos, y en todo proceso asumir una responsabilidad con respecto a las preocupaciones ecológicas evidentes y actuales que se viven en el mundo. Por su parte, el Plan Nacional de Desarrollo (PND) 2018-2022 (Ley 1995 de 2019) da pautas que orientan a entender la aplicación del GM en los negocios verdes; es visible cuando están enfocados en generar impactos ambientales positivos, por ejemplo, la implementación de acciones para mejorar la eficiencia en el uso del agua, adoptar tecnología para la gestión eficiente de la energía, conservar los recursos naturales, reducir la contaminación, optimizar recursos, entre otras. Lo que, en resumen, origina la idea para que, en este artículo, se vea el Gm como la aplicación desde el mercado de procesos que conducen a un consumo responsable, tanto desde un punto de vista ambiental que aporta a la sostenibilidad, como desde acciones responsables que llegan a otros ámbitos de la sostenibilidad. A tal efecto, para este estudio se realiza un proceso que busca un grupo de personas que gestionan procesos de marketing en empresas, y personas en Pereira, para recoger información con la que se analizan bases teóricas y procedimentales. Así, a partir de sus conocimientos, prácticas y actitudes 
relacionadas con la aplicación de GM, se describen pautas que permitan a las organizaciones y a los profesionales del marketing tomar decisiones en procesos que integren la perspectiva del GM. Además, se contrasta con lo que consideran los consumidores y lo que pueden hacer los profesionales del mercadeo.

El estudio brinda bases para aportar soluciones a las necesidades de las organizaciones frente al tema de integrar procesos sostenibles, desde el GM, partiendo del reconocimiento de prácticas, lineamientos, conocimientos y beneficios de su empleo.

\section{Revisión de la literatura}

El interés en el GM ha surgido ante la evidencia de los impactos del sistema productivo y de consumo, que han devenido en problemas a nivel planetario, como ha sido el calentamiento global, la deforestación y la contaminación, que según Domínguez (2015) "es un proceso cíclico que involucra todos los ambientes: aire, agua y suelo, y desde cualquier perspectiva, a los seres vivos" (párr. 1); como también la escasez de agua y energía, la extinción de especies y la amenaza a la biodiversidad, entre otros. Por eso Castellano y Urdaneta (2015) recalcan que "es importante resaltar que el GM no puede verse solo como tendencia, sino que debe asumirse como una 'forma de vida', una filosofía de trabajo" (p. 478).

Bajo esta óptica, es fundamental que los gobiernos controlen e implementen conciencia verde (Johnstone \& Hooper, 2016); además, según Jenkin et al. (2014) existen técnicas de marketing que promueven objetivos sociales; y Cervera Taulet et al. (2010) añaden que es importante la comprensión de la ética en el marketing. En el caso de Colombia, el Ministerio de Ambiente y Desarrollo Sostenible es el agente de control y verificación de criterios orientados hacia los negocios verdes, que "define lineamientos y fomenta la promoción tanto de la oferta como de la demanda de negocios verdes y sostenibles en el país, a través de la aplicación adecuada de instrumentos, incentivos, coordinación, y articulación institucional que conlleve al crecimiento económico" (MinAmbiente, 2016b, p. 2). A partir de allí, se crearon los lineamientos de los negocios verdes, mediante el diseño del Plan Nacional de Negocios Verdes, que establece 12 criterios necesarios para que las entidades puedan ser 
reconocidas como negocio verde. La viabilidad económica de la empresa hace referencia a la sostenibilidad del negocio a nivel técnico, financiero, legal, comercial y organizacional (MinAmbiente, 2014).

Los lineamientos y la supervisión son necesarios, pues como lo exponen Kotler y Keller (2016) debido al creciente interés de los consumidores en la sostenibilidad, se ha producido el fenómeno del lavado verde conocido como Greenwashing (p. 82), práctica con la cual algunas empresas desean demostrar un compromiso ambiental, cuando en realidad no lo están cumpliendo. Por esto, para los negocios que no cumplan con los 12 criterios que se exponen en la tabla 1 , la oficina de negocios verdes ha desarrollado un plan que busca implementar mejoras para que se cumplan todos los aspectos a cabalidad. En la página web de MinAmbiente (2016b) se encuentran los instructivos y los formatos que deben diligenciarse para que las empresas puedan adelantar el proceso de transformación hacia negocios verdes (figura 1).

Tabla 1. Criterios de verificación

\section{Nivel 1 - Criterios}

- Viabilidad económica el negocio

- Impacto ambiental positivo y contribución a la conservación y preservación de los recursos ecosistémicos

- Enfoque ciclo de vida del bien o servicio

- Vida útil

- Sustitución de sustancias o materiales peligrosos

- Reciclabilidad y uso de materiales reciclados

- Uso eficiente y sostenible de recursos para la producción de bienes o servicios

- Responsabilidad social al interior de la empresa

- Responsabilidad social en la cadena de valor de la empresa

- Responsabilidad social hacia el exterior de la empresa

- Comunicación de atributos del bien o servicio

Nivel 2 - Criterios

- Esquemas, programas o reconocimientos ambientales o sociales implementados o recibidos

Fuente: Plan nacional de negocios verdes (MinAmbiente, 2014). 


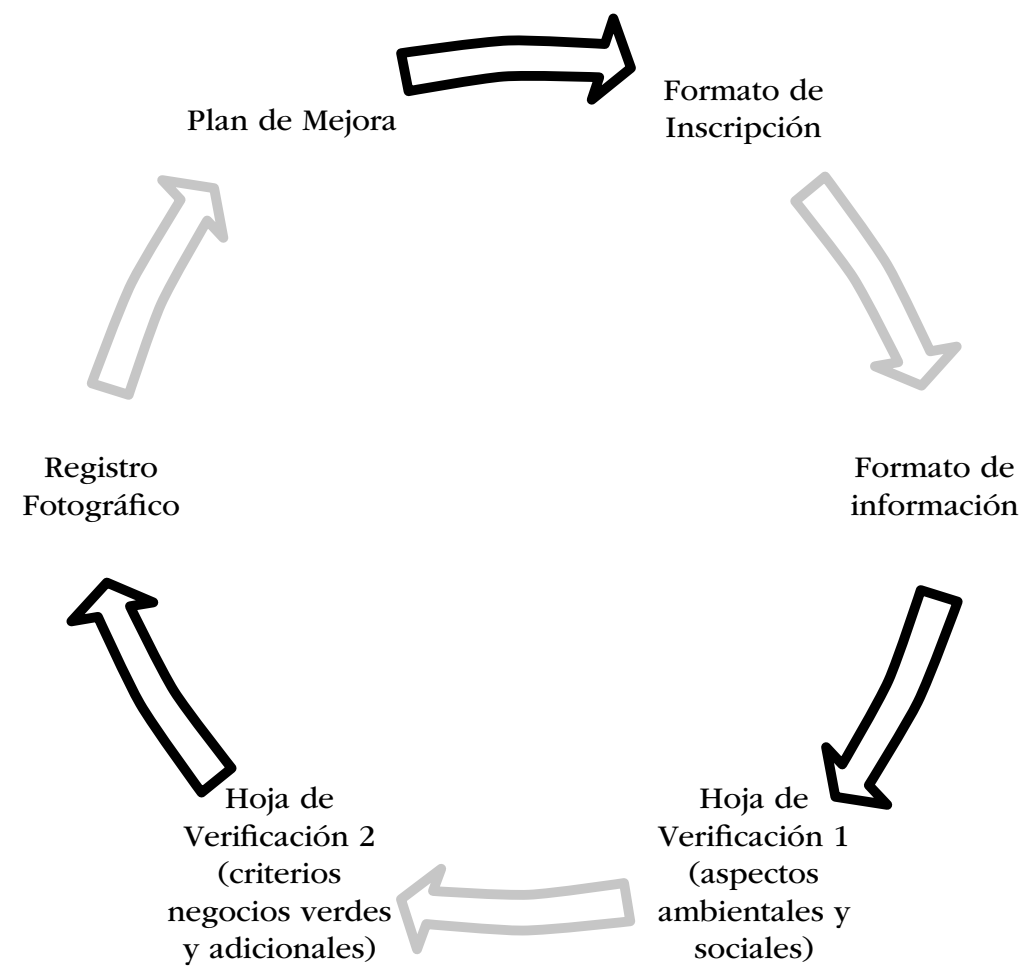

Figura 1. Formatos de los Negocios Verdes

Fuente: Minambiente (2016b, párr. 2).

\subsection{Green marketing}

Kotler y Keller (2012) afirman que el GM es una evolución del marketing social, ya que se sitúa como intermediario entre los intereses individuales y el interés público, y según Kharde (2016) se inserta dentro del marketing orientado a satisfacer las necesidades de los consumidores de manera rentable, pero hacia un sentido de sostenibilidad.

Dias (2008) señala que el GM es un término que se remonta a 1975 con temas de sostenibilidad expuestos en la conferencia impartida por la American Marketing Asociation (AMA). El GM es explicado por Santesmases (citado en Salas Canales, 2018) como la comercialización de productos elaborados con material reciclado, amigables con el medio ambiente y que contaminen poco. Para lograrlo, Shrikanth y Raju (2012) plantean que esto implica desarrollar productos de buena calidad, que satisfagan las necesidades y los deseos de los consumidores, pero de una manera amigable con el medio ambiente. 
Por eso hay que integrar la premisa del GM a los componentes de la mezcla de marketing que tienen gran importancia para Kharde (2016) en la adopción desde el green marketing hasta el green marketing mix, en el que el producto debe ser ecológico y no contaminar, al igual que el embalaje, pues como afirman Willums (1998) y Polonsky y Rosenberger (2001) se le está dando mucha importancia al canal inverso y la comunicación debe hacer énfasis en aspectos ambientales para contribuir a la creación de una conciencia ecológica (Das et al., 2012), que puedan mostrar los atributos de manera eficiente (Yazdanifard \& Mercy, 2011) y que generen emociones para persuadir al cliente (Bathia \& Jain, 2013).

De acuerdo con las anteriores estrategias verdes, enfocadas al marketing mix de un producto o servicio, se presenta la oportunidad de indicar las características que tienen los productos o servicios verdes, que retoman Dangelico y Pontrandolfo (2010); igualmente, para Elkington y Hailes (1988), estos productos no ponen en peligro la salud del consumidor; para Simon (1992) no impactan las especies y tampoco contaminan; Schmidheiny (1992) asegura que aumentan la vida del producto; Peattie (1995) indica que se pueden reciclar; Robèrt (1995) señala que evitan el uso de materiales tóxicos; Roy et al. (1996) estiman que se fabrican de manera local para evitar el transporte; y finalmente, Luttropp y Lagerstedt (2006) afirman que deben promover la reparación y el reciclaje.

Por otro lado, la historia ambiental muestra las crisis ambientales resultantes de la depredación de recursos naturales hasta la extinción (Tommasino et al., 2005) que según Leff (2018) generan desigualdad social y pobreza. Al respecto, Sharma e Iyer (2012) exponen las consecuencias del desarrollo de productos con recursos limitados, RCPD (por sus siglas en inglés, Resource Constrained Product Development) y la importancia de reducir el impacto generado en la producción; mencionan tres formas específicas para asegurar la sostenibilidad del medio ambiente: 1) crear productos con menos recursos, 2) asegurar la eficiencia en la cadena de suministro, y 3) eliminar la vieja tecnología que utilice mucha energía y recursos; por esto, aseguran que desarrollar productos con RCPD enfocados en utilizar menos material, trae ventajas competitivas y proporciona importantes beneficios para la sostenibilidad. 


\subsection{Tendencias de consumo orientadas por la sostenibilidad}

Debido al interés por crear entornos positivos para la sociedad y atender los crecientes problemas ambientales y de salud que se están presentando, se ha consolidado una de las tendencias más fuertes de este último siglo dirigida al cuidado del medio ambiente y de la salud de las personas; tendencia que involucra igualmente a las empresas, al gobierno y las instituciones para generar alternativas que conlleven impactos positivos en el medio ambiente y la sociedad.

Según el estudio de consumo responsable en Colombia realizado por Peñalosa Otero y López Celis (2018), se evidencia una actitud positiva con respecto al consumo socialmente responsable. De la misma manera, se infiere una conciencia no solo acerca del impacto de la propia conducta en el consumo, sino también de la exigencia y la consideración.

Esta tendencia viene acompañada de personas mucho más conscientes y responsables al momento de consumir un producto o servicio. Entre las tendencias más fuertes del siglo xxI, se identifica la importancia que para millones de personas ha significado el cuidado del medio ambiente y la salud. Ahora estas personas están dispuestas a pagar un poco más por productos o servicios que contribuyan a cuidar el planeta y sean benéficos para la salud y el bienestar personal (Cardona Arbeláez, 2018, p. 3).

Esto quiere decir que el mercado de consumos verdes, ecológicos o sostenibles ha venido teniendo un crecimiento importante en los últimos años. Euromonitor ha mostrado entre las diez tendencias globales de consumo aquellas relacionadas con la sostenibilidad en sus diferentes dimensiones, por ejemplo, reconstruir para mejorar, se enfoca en la protección de la salud, la sociedad y el planeta. La prioridad de las empresas debe ser desarrollar un mundo de manera sostenible. A esto se agrega la tendencia de inquietos y rebeldes, la cual expone que en la era digital los consumidores están exigiendo a las empresas tener en sus objetivos una comunicación verídica. También se identifica la tendencia de ahorradores reflexivos, relacionada con un consumo responsable que apunta a que las empresas proporcionen calidad y precio con productos y servicios que cuiden la salud, el bienestar y el autocuidado (Westbrook \& Angus, s. f.). Estas tendencias impulsan, en últimas, a que la industria asimile este reto grandísimo de ser sostenible sin dejar de ser rentable. 


\subsection{Greenwashing}

Northen (2011) asocia el término greenwashing a la desinformación que difunde una organización con el fin de promover una imagen pública ambientalista, cuando realmente no lo cumple. Es "una comunicación deliberada meramente simbólica, una fachada de prácticas para generar beneficios" (Cliath, 2007, y Forbes \& Jermier, 2012, citados en Bowen \& Aragon, 2014, p. 107). Según Hallama et al. (2011), ese suministro de información distorsionada emplea información medioambiental selectiva, con el fin de producir en la mente de los consumidores una imagen encubierta, la cual Greenpeace denuncia como engaño sobre prácticas responsables verdes (Gallicano, 2011 y Bruno \& Greer 1992, citados en Hallama et al., 2011). Santamaría (2018) indica que las organizaciones implementan el greenwashing para responder a las presiones sociales. También, es importante señalar que, según Guerreiro y Pacheco (2021), existe una mediación completa entre la percepción de lavado verde y la intención de compra a través de la confianza verde, lo que conlleva a un escepticismo verde, es decir, un bajo nivel de confianza en productos o servicios ecológicos. Para Alqadri (2021), la confianza verde tiene un efecto directo y significativo en la intención de recompra.

La publicidad es un factor importante, por cuanto los mensajes verdes tienen repercusiones sobre los consumidores a nivel emocional, porque cuando se consumen productos verdes hay sentimientos de altruismo, participación y contacto con la naturaleza (Hartmann, citado por Hallama et al, 2011, p. 3). Stauber y Rampton (1995) (citados por Hallama, 2011, p. 11) aseguran que las empresas utilizan la publicidad para llamar la atención del público y manipularlo, y establecer presión externa para llamar la atención en unos aspectos y desviarla de otros que también pueden ser importantes, y está comprobado según Navarro (1971) que la publicidad es clave para posicionar productos y empresas.

\subsection{Políticas y regulaciones}

En Colombia, mediante la Política Nacional de Producción Limpia se busca promover el mejoramiento ambiental para la competitividad empresarial y la transformación productiva. Asimismo, se cuenta con políticas ambientales corporativas que manifiestan interés por implementar buenas prácticas empresariales. Colombia forma parte de la Agenda de 
las Naciones Unidas 2030 (MinAmbiente, 2016a) con el fin de generar formas alternativas que permitan el uso sostenible del capital natural. Todo esto, se direcciona a acabar la pobreza, proteger el planeta y asegurar la paz y la prosperidad entre todas las personas.

También se tiene el Plan Nacional de Negocios Verdes (MinAmbiente, 2014), que señala aspectos de productos y servicios en contexto de sostenibilidad, que permitan identificar negocios verdes, sin disminuir su calidad, pero que mitiguen o reduzcan los daños que puedan causar en el medio ambiente.

Así mismo, se han establecido normativas aplicables en Colombia como el fomento del uso racional y eficiente de la energía (Ley 697 de 2001); el consumo responsable del agua (Ley 373 de 1997); y promover la preservación del medio ambiente y la seguridad de los trabajadores (Ley 9 de 1979).

Finalmente, es importante señalar que, Colombia, como miembro de la onu, también ha adoptado los Objetivos de Desarrollo Sostenible, reglamentados en el Decreto 280 de 2015: "Por el cual se crea la Comisión Interinstitucional de Alto Nivel para el alistamiento y la efectiva implementación de la Agenda de Desarrollo Post 2015 y sus Objetivos de Desarrollo Sostenible - oDs", como una oportunidad para generar cambios culturales que permitan mejorar la calidad de vida de los habitantes del país, con un impulso dado por el gobierno Nacional. Con respecto al objetivo sostenible 12 "Producción y consumo responsable", la meta del Gobierno, coherente con la presente investigación, pretende: "Generar formas de producción alternativas que permitan el uso sostenible del capital natural, se pretende impulsar y verificar 1436 negocios verdes en 2022", alineado con el propósito 12.6, "Fomentar prácticas sostenibles en las empresas" (PNUD et al., 2015).

A pesar de las distintas políticas para el control y promoción de la producción de productos y servicios verdes, es fundamental reconocer que el compromiso social por cambiar hábitos de producción y de consumo es esencial para vivenciar un cambio real. Esto debido a que, desde las grandes empresas, hay suficiente poder para influir sobre la legislación y no cumplir con esta, y desde el consumidor, a pesar de que existen productos sostenibles verificables y medidas que orientan a desarrollar acciones favorables, no se cumplen desde lo personal. 


\section{Metodología}

Este artículo es resultado de un estudio exploratorio mixto realizado en la ciudad de Pereira en Colombia, con el propósito de identificar actitudes, conocimientos y prácticas, entre otros constructos, reportados por las personas participantes del estudio para orientar la aplicación del GM en organizaciones, integrando perspectivas de consumidores, empresas y profesionales del marketing.

Para la recolección de la información comprendida entre mayo a diciembre de 2020, se efectuaron actividades mediante metodología cualitativa, que integra una revisión documental de publicaciones y estudios de los últimos diez años, las cuales se escogieron de acuerdo con su indexación y citación; y políticas y regulaciones con aplicación al contexto y que orientaran las categorías de análisis. El proceso continuó con diez (10) entrevistas a empresarios de organizaciones de la ciudad de Pereira en dos (2) rondas de reuniones; la primera, exploratoria para establecer su relación con aspectos de sus labores; y la segunda, en relación con diferentes prácticas responsables y temas relacionados con GM. Los criterios de muestreo responden al perfil de su gestión relacionada con procesos de mercadeo y actividades con procesos sostenibles, con el propósito de evidenciar el conocimiento del término Green Marketing, tener conciencia del impacto generado por el desarrollo de la actividad productiva y conocimiento de los beneficios del GM. Previamente, se formuló la entrevista piloto, para verificar y ajustar el cuestionario de acuerdo con elementos encontrados en la entrevista o que pudieran aportar mayor información a la investigación.

También se hizo la aplicación de encuestas en formato digital distribuidas por medio de WhatsApp, en la que participaron 97 consumidores, con el objetivo de indagar sobre el conocimiento de problemáticas ambientales y su compromiso hacia el consumo de productos o servicios con menor impacto sobre el medio ambiente; con muestreo no probabilístico para una población finita cualitativa respondiendo a un perfil por conveniencia, mediante un filtro para que las personas respondieran tener interés por la sostenibilidad en sus procesos de consumo de servicios/productos sostenibles. 
Finalmente, con propósitos de contrastación de las evidencias y datos en términos de transferibilidad, se hizo un (1) Grupo focal con siete especialistas en Marketing egresados de la Universidad EAfIT, a través de una plataforma de comunicación para el reconocimiento del GM y la aplicabilidad en sus roles. Las entrevistas y sesiones con el grupo se hicieron mediante plataformas de comunicación y colaboración dado el momento coyuntural ocasionado por la pandemia.

Como criterios de muestreo se buscó que el perfil de los entrevistados fuera gerencial y directivo en diferentes sectores, con el fin de identificar el compromiso gerencial en el cumplimiento de las disposiciones planificadas para el seguimiento de objetivos e indicadores que impactan el aspecto ambiental.

Para la encuesta se elaboró un cuestionario dirigido a personas residentes de Pereira y que afirmaran tener interés o preferencia de consumo de productos con características ecoamigables. El tamaño de la muestra se estableció usando la siguiente ecuación:

\subsection{Tamaño de la muestra}

$$
\frac{\frac{z^{2}(p)(1-p)}{e^{2}}}{1+\frac{z^{2}(p)(1-p)}{e^{2} N}}
$$

En la cual el tamaño de la población corresponde a 477027 (habitantes de Pereira al momento del estudio), con margen de error e $=0.5$ y nivel de confianza de 95\% (1.96), considerando la desviación estándar.

Tabla 2. Perfiles de los participantes entrevistados

\begin{tabular}{llll}
\hline \multicolumn{1}{c}{ Código } & \multicolumn{1}{c}{ Género } & \multicolumn{1}{c}{$\begin{array}{c}\text { Cargo en la } \\
\text { empresa }\end{array}$} & \multicolumn{1}{c}{ Sector al que pertenece la empresa } \\
\hline PIL-001 & Femenino & Coordinación & Servicios de aseo y mantenimiento \\
\hline ENT-001 & Masculino & Gerente & Servicios arrendamiento equipos \\
\hline ENT-002 & Masculino & Representante Legal & Construcción y mantenimiento equipos periféricos \\
\hline ENT-003 & Masculino & Representante Legal & Construcción \\
\hline ENT-004 & Femenino & Gerente & Servicio de lavandería \\
\hline ENT-005 & Femenino & Gerente & Comercios batidos de fruta \\
\hline
\end{tabular}




\begin{tabular}{llll}
\hline \multicolumn{1}{c}{ Código } & \multicolumn{1}{c}{ Género } & \multicolumn{1}{c}{$\begin{array}{c}\text { Cargo en la } \\
\text { empresa }\end{array}$} & \multicolumn{1}{c}{ Sector al que pertenece la empresa } \\
\hline ENT-006 & Femenino & Gerente Comercial & Manufactura- muebles \\
\hline ENT-007 & Femenino & Representante Legal & Comercio de repuestos y aceites \\
\hline ENT-008 & Femenino & Representante Legal & Comercio \\
\hline ENT-009 & Femenino & Gerente & Manufactura. Producción café \\
\hline
\end{tabular}

Fuente: elaboración propia.

Para el Grupo Focal respondieron a la convocatoria siete especialistas en Marketing. Se realizó con el propósito de identificar los beneficios de la implementación del green marketing y la orientación hacia el consumo responsable/responsabilidad social ambiental y se indagó acerca de su nivel de conocimiento sobre el greenwashing.

Tabla 3. Participantes del grupo focal

\begin{tabular}{lll}
\hline \multicolumn{1}{c}{ Código } & \multicolumn{1}{c}{ Género } & \multicolumn{1}{c}{ Campo De Acción } \\
\hline P 1 & Femenino & Licores \\
\hline P 2 & Femenino & Retail \\
\hline P 3 & Femenino & Salud \\
\hline P 4 & Femenino & Servicios financieros \\
\hline P 5 & Femenino & Detalles sorpresa \\
\hline P 6 & Masculino & Transporte \\
\hline P 7 & Masculino & Consultoría \\
\hline
\end{tabular}

Fuente: elaboración propia.

Para el análisis de la información obtenida, se hizo una triangulación confrontando los datos recopilados de las diferentes fuentes de información con soporte para la interpretación de categorías en la información proporcionada por las fuentes secundarias. El tipo de análisis aplicado tiene un enfoque hermenéutico, el análisis se hace en función de la revisión de la literatura y las categorías de análisis: conocimiento, interés e implementación de GM, orientación hacia consumo responsable, que se analizó mediante matrices de análisis por objetivos, previa codificación y categorización en CADQAS, para luego hacer triangulación con el contenido de las encuestas y se contrastó para construir los modelos con los especialistas en mercadeo. 
Fase 1. Preparatoria

-Rastreo de información general y fuentes académicas.

- Entidades oficiales, ODS

- Revisión de requisitos normativos en página del

Ministerio de Ambiente y Desarrollo Sostenible.

- Documentación de aspectos necesarios para el cumplimiento de exigencias de negocios verdes.
Fase 2. Trabajo de campo

- Definición y convocatoria de fuentes y técnicas para recolectar la información.

- Diseño de instrumentos para recolectar la información.

- Aplicación de los instrumentos.
Contrastación y

análisis constante
Fase 3. Analítica

- Documentación de los resultados obtenidos. - Análisis conceptual de los datos recopilados. -Verificación de cumplimiento de los objetivos propuestos.

-Triangulación
Fase 4. Informativa

- Documentación de la información en informe final. - Socialización de resultados frente a pares y jurados

Figura 2. Fases de la investigación

Fuente: elaboración propia.

\section{Análisis de hallazgos y resultados}

El marketing trabaja para generar lazos entre marcas y consumidores, así como impulsar el aumento de la demanda; pero bajo la óptica del GM, más que cumplir con dicho objetivo, se debe buscar un impacto positivo para los consumidores, las empresas y la sociedad en términos ambientales, además de contribuir con intervenciones enfocadas a propiciar mejores condiciones para la salud y el bienestar asociadas a lo sostenible. Para saber cuál es el conocimiento general del marketing verde por parte de las empresas entrevistadas, si lo que hacen puede responder a lo que requieren los consumidores y lo que pueden hacer los profesionales del mercadeo, en la siguiente sección se aportan evidencias de lo que se hace en esas empresas, así como reflexiones que dan cuenta de lo que piensan los consumidores, con lo que se proponen dos modelos para ver el rol de empresas y consumidores verdes y se verifican desde la mirada de un grupo de especialistas en mercadeo. 
El GM es definido por ENT001, como las prácticas económicas con el mínimo impacto ambiental posible, mejorando los procesos productivos hacia una cultura sostenible. Sin embargo, para las demás personas de las empresas a las que se acercó el estudio, señalaron desconocimiento, pero recalcaron interés sobre el tema o al menos la inquietud en este aspecto.

Frente a la importancia de tener un referente para consultas o acompañamiento en el medio con todo lo relacionado al GM entre quienes participaron en la investigación, el conocimiento sobre empresas consultoras en green marketing se enfoca a las empresas certificadoras: ENT002 y ENT003 manifiestan conocer las normas ISO 9001 (Calidad en procesos), 18001 (Ambiental) y 45001 (Seguridad y salud en el trabajo).

Ese desconocimiento, ese interés y esa oportunidad llevaron a que se buscara responder a sus expectativas, pero primero estableciendo el grado de conocimiento o acercamiento a lo que constituye el GM.

El interés de quienes integran las organizaciones de Pereira se relaciona con su conocimiento y percepción de los problemas ambientales generados por la operación empresarial, por ejemplo, PIL001, quien hace parte de una empresa de servicios de aseo y mantenimiento, considera que estos problemas se relacionan con "Contaminación de los ríos, contaminación del aire, cambio climático, deshielo de los polos, extinción de fauna y flora"; ENT001 coincide e identifica "el calentamiento global, la deforestación, la contaminación" y agrega "los problemas de la calidad de aire"; ENT004 especifica en la "contaminación de ríos, la tala de árboles, afectación y la extinción de la fauna y la flora"; y ENT005 incluye la "contaminación visual".

En otro aspecto, hay quienes de inmediato relacionan el rol de las organizaciones con las problemáticas; lo hacen con la generación de residuos: ENT002, quien hace parte de una empresa de servicios de arrendamiento de equipos, expone que "en empresas que ofrecen soluciones en equipos periféricos, los mayores impactos generados son los residuos resultantes de la actividad productiva, por ejemplo, cables. Sin embargo, dichos elementos en ocasiones pueden volverse a utilizar”. ENT003, por su parte, también enfocó la respuesta en la generación de residuos, pese a que el tratamiento es totalmente diferente: "en el sector de la construcción es muy común el problema de los residuos sólidos, especialmente escombros producto de la actividad económica". Coincide con el entrevistado ENT001, en 
cuanto a lo que menciona en relación con "la contaminación del recurso aire"; además, incluye "la generación de residuos químicos como pinturas y sobrantes de construcción".

Teniendo en cuenta las anteriores respuestas, se puede establecer que los entrevistados conocen los problemas ambientales actuales en aspectos como el agotamiento de los recursos naturales, la contaminación de los recursos agua, aire y suelo, la contaminación visual, además de la afectación a la fauna, flora y salud humana, la biodiversidad y el manejo de residuos.

Con base en ese conocimiento, en las empresas de los entrevistados se promueve actualmente el consumo responsable y el uso de productos o servicios verdes o sostenibles, y se considera la importancia del compromiso frente al consumo responsable. ENT001 afirma que lo realizan por medio de "adquisiciones de nuevos equipos". Para el caso de la empresa de ENT002, se promueve el consumo responsable "mencionando las prácticas a nivel ambiental implementadas por la empresa”. En cinco de las empresas se promueve con campañas educativas a través de capacitación, inducción y reinducción, sensibilizaciones y retroalimentación con quien se encargue de los procesos ambientales (ENT003, ЕNT009, ЕNT008, ENT006, ENT007).

Por otro lado, se contempla lo relacionado con las características del empaque del producto, los efectos de los empaques y la disposición final. Para ENT006, si el producto "es empacado en plástico grueso no biodegradable [...] el impacto sobre el medio ambiente es importante, porque, si el cliente realiza una mala disposición, podrían contaminar los ríos”; ENT005 manifiesta que los empaques de "plástico hermético, no cuentan con características biodegradables y tienen efectos conocidos sobre los ecosistemas" y puede darse que "no haya buena cultura en cuanto al manejo de los residuos por parte del cliente final". El empaque de los productos requiere especial atención, puesto que, aunque las empresas procuran el cuidado ambiental en los productos, el efecto generado por los empaques puede ser totalmente contrario y para que las empresas puedan ser reconocidas como verdes, deben considerar en el ciclo de vida del producto al empaque.

En el reconocimiento de la práctica surgen propuestas para afrontar la crisis ambiental, comenzando por la educación y la formación en el tema como expone ENT003 al decir que "es necesario ofrecer capacitaciones frecuentes para vincular todos los niveles de 
la empresa", propiciando espacios para hacerlo, como plantea ENT006: "Creería que se deberían tomar espacios para la capacitación del personal y sensibilización al personal para el control y uso responsable de recursos". PIL001 plantea "campañas de educación a la comunidad para el buen uso de los recursos naturales, implementación de buenas prácticas en todos los procesos productivos, para reducir y controlar el manejo de residuos, y sensibilización del personal en temas ambientales". Campañas que, para ENT007 y ENT009, deben estar enfocadas en el cambio actitudinal.

Además, esto lleva a que se hagan revisiones a procesos internos de las organizaciones: para ENT002 esa formación "incluye la revisión de los procesos internos de la empresa para establecer acciones para mitigarlos". Mientras que ENT004 manifiesta que "las estrategias deben aplicarse directamente sobre los procesos productivos y que, además, exista un uso de las materias primas biodegradables, reducción del consumo de recursos, reutilización y reciclaje".

ENT008 sugiere que "debe existir mayor regulación legal y sancionatoria para que las empresas cambien la cultura" y, en efecto, hoy se cuenta con elementos esenciales que son de obligatorio cumplimiento, en el evento de hacerse la transición hacia negocios verdes. Dichos aspectos hacen parte de los cuestionamientos relacionados con el lineamiento de impacto ambiental positivo, en lo que corresponde a las acciones para la conservación de los ecosistemas y a las acciones para la disminución de la contaminación. Entonces, lo primero que se necesita para que una organización sea reconocida como negocio verde, es que ya integre procesos relacionados, que luego le permitan ser reconocida como negocio verde. Lo cual implica que reflexionen y recopilen información disponible sobre los mecanismos para reducir los impactos ambientales establecidos en la empresa.

Entre esas acciones se mencionan la reducción del consumo o el consumo racional "del agua y de la energía" (ENT001, enT003), "la disposición y separación de residuos" (ENT001, ENT002, ENT003), aunada a la "optimización de recursos" (ENT003) que en la organización de ENT006 - dedicada a la manufactura de muebles-, se trata de "reciclar cortes de espuma para convertirlos en picadillo". Respuestas que hacen parte de los procesos misionales de la empresa, exceptuando casos como el de ENT007, que comenta que en su empresa de comercio de repuestos y aceites "no cuenta con cadena de producción", pero sí hay inquietud al 
respecto, todos reflexionaron sobre la forma cómo la empresa puede garantizar un mínimo impacto ambiental posible en los ecosistemas.

Los participantes destacan las prácticas de cuidado ambiental, para afrontar la crisis ambiental, que implementan en las empresas, tales como: "ahorro de agua, separación de residuos y consumo responsable de energía" (ENT001 y ENT002); ENT004 explica que "se realiza el control de ciclos de lavado para minimizar consumo de agua, control de consumo de energía, uso racional de recursos"; y ENT003 expone que son "las enfocadas en el control de los residuos generados y el fomento de reciclaje y reutilización de elementos".

También consideran importante contar con estrategias relacionadas al cuidado y a la preservación del medio ambiente. PIL001 considera que debe haber "comunicación clara con los clientes, revisión detallada de las características del servicio”, a lo que ENT001 agrega que, para tal efecto, debería haber "información sobre las características de los servicios, mención sobre acciones al interior de la empresa y la información sobre los procedimientos de ahorro de los recursos"; ENT009 propone la "Reutilización del plástico a cambio de descuento para el cliente que lo devuelva"; ENT007 menciona la concientización ambiental; ENT005 habla de estrategias de sensibilización y uso adecuado del plástico; y ENT008 y ENT004 plantean mantener la estrategia del plástico biodegradable.

Por otra parte, algunos participantes sugieren estrategias como "plantear lugares de acopio de plástico del producto para una adecuada disposición final" (ENT006); hacer "capacitación colectiva, premios para trabajadores que contribuyan a ideas para minimización de residuos" (ENT003); y, además de formación, el "establecimiento de bonificaciones para los trabajadores" (ENT002). También, parte de las personas entrevistadas hicieron alusión a la comunicación de las bondades de los productos o servicios a los clientes.

La integración de GM en la filosofía como respuesta a las regulaciones para saber cómo ser una empresa verde, debe empezar por conocer los lineamientos para serlo y aunque PIL001 manifiesta solo saber que "en Colombia existen dichos lineamientos" y ENT008 reconoce: "Solo conozco lo de la etiqueta ecológica, que es el sello ambiental colombiano", la mayoría de las personas participantes manifestaron no conocerlos, pero quisieran saber más del tema. Por esto, es importante proveer a las empresas de estrategias que permitan conocer los lineamientos para que puedan ser reconocidas como negocios verdes. 
La forma como se integra el cuidado del medio ambiente con la filosofía de la empresa es fundamental en los procesos de concientización, los cuales pueden ser "controles básicos para proteger el medio ambiente" (ENT001), o pueden establecerse desde la planeación, que según ENT002, se gestiona "desde la gerencia, direccionando políticas, objetivos y metas", "propiciando formación”, como lo expone ENT005, quien explica además que en la empresa se "dictan conferencias sobre el uso adecuado de los recursos naturales" y tanto ENT009 como ENT007 describen estos procesos de "concientización y capacitación de los trabajadores sobre la conservación del medio ambiente". Es clave que se instaure mediante "la adopción de valores corporativos" (ENT008) o se "[tenga] definida una política ambiental que se integra con los otros sistemas" (PIL001), por lo cual esa integración sería parte del pensamiento organizacional.

En todo caso, hay saberes previos que pueden reconocerse porque pueden ser estratégicos en una eventual implementación del green marketing. Esto es, desde la gestión que realizan las personas entrevistadas, hay conocimientos que se tendrían en cuenta. Para algunos radica en diagnosticar la empresa, por ejemplo, PIL001 plantea hacerlo desde el manejo de los residuos e implementar políticas de reutilización, reciclaje y reúso, planteando que se "iniciaría con un diagnóstico organizacional para definir en qué condiciones se encuentra la empresa frente a los requisitos definidos y realizar acciones de mejoramiento"; por su parte ENT001 haría "verificación documental, identificación de requisitos, creación de documentos, reestructuración de procesos y auditoría legal"; ENT002 realizaría "un proceso iniciando por la fase investigación (exigencias, componentes y lineamiento), seguido por el diagnóstico (verificación de cumplimiento) y finalizando con la puesta en marcha (análisis detallado del costo y beneficio de la decisión)". Sobre esto, ENT003 resume diciendo que "el proceso que seguiría para ser reconocido como negocio verde es similar al de cualquier otra certificación, que iniciaría con el diagnóstico y continuaría con la medición, acciones de mejora y seguimiento".

Finalmente, también se relaciona con decisiones estratégicas, ENT004 manifiesta que implementaría green marketing en una empresa mediante el "cambio de proveedores si los productos no son biodegradables, optimización de recursos naturales, renovación maquinaria”. 
Teniendo en cuenta lo anterior, es necesario reconocer los lineamientos requeridos para obtener el reconocimiento de conceptos como negocios verdes y la forma como se regulan las buenas prácticas ambientales en la organización. Al respecto, quienes participaron exponen actividades como "visitas y registros definidos" (PIL001), "programas de seguimiento" (ENT001) o, como lo comenta ENT003, con "control desde la gerencia, por medio de indicadores", que puede ser "la medición por o desde los clientes, a través de profesionales en el área ambiental”. Es pertinente el seguimiento que se lleva a cabo con personal que, para el caso de la empresa de ENT006, es el jefe de producción quien "verifica el manejo correcto de los recursos naturales"; en la multinacional donde trabaja ENT009 se aplica "con sistemas integrados de gestión certificados, incluido el sistema de gestión ambiental, debidamente certificados"; en la empresa de ENT007, lo regulan mediante "el sistema de gestión de calidad, implementando las prácticas de reciclaje"; y en la de ENT008, cuentan con "un indicador para medir desechos, con incentivos para los trabajadores".

Todas las empresas entrevistadas cuentan con controles para garantizar buenas prácticas

ambientales, los cuales se respaldan con los soportes documentales correspondientes, que confirman si las estrategias para minimizar los impactos ambientales son coherentes o no, de acuerdo con la naturaleza específica del negocio.

\subsection{Beneficios y oportunidades con la implementación de GM}

Implementar el GM en las empresas, según quienes fueron entrevistados, tiene efectos en la reputación de la organización: para ENT006 se "genera un estatus para la empresa, con factores diferenciadores con la competencia", "considera que beneficia principalmente los ecosistemas" y recalca que además "proporciona a la empresa tranquilidad, posibilidad de incrementar ventas y categorización de la industria”. Este planteamiento se puede evidenciar en lo que manifiesta ENT007, quien estima que "los beneficios principalmente son para el consumidor", y, por lo tanto, "las empresas con estas iniciativas son más atractivas para los clientes", lo que considera ENT005 al decir que "los mayores beneficiados son los ecosistemas", o como expone ENT008 porque "genera mejoramiento empresarial y ambiental, beneficia a toda la población en general, mediante la disminución del impacto ambiental”.

Con este fin, se debe controlar el greenwashing con prácticas coherentes con la sostenibilidad. Los expertos en marketing discutieron frente a imágenes relacionadas con 
negocios verdes, que, entre otros ejemplos, se ilustra el uso de un slogan que expone el origen natural del endulzante de una bebida gaseosa, a la que se le agrega Life en el logo, sin brindar una idea sobre lo que contiene, que, además, en campaña se presenta una imagen que favorece el cuidado del medio ambiente y se emplea el verde buscando la denotación. El grupo comenta, igualmente, que la imagen empresarial debe incluir en su desarrollo aspectos que enuncien la intención, para permitir una comprensión del sentido ambientalmente responsable.

Por otro lado, los expertos en marketing piensan que los productos y servicios con objetivos ambientales y sociales deben tener una serie de características, que como establece P2 "los productos tecnológicos se deberían poder cargar con energía solar", para lo que P5 respalda y añade que "las partes plásticas se deberían elaborar con plástico reciclado extraído del mar en su mayoría", igualmente, señalan que las organizaciones deberían comunicar mejor lo que se está haciendo en el interior para mitigar el daño ambiental, como también, tener programas de formación para sus clientes, dado el desconocimiento de muchos acerca de procesos de reciclaje, de reúso, de disposición final de los empaques, reconocimiento de la problemática ambiental, entre otros.

Así mismo, discuten sobre empresas de alimentos y señalan que es muy importante que implementen procesos adecuados en la producción, tales como sistemas de riego (P3), ahorro de agua y energía (P4), o como enfatiza P7 controlar las actividades de ganadería por su grado de contaminación en la tierra. También, aseguran que es indispensable más rigurosidad en el control y vigilancia por parte de los entes gubernamentales en los procesos productivos, de distribución, de reciclaje, de uso de recursos, entre otros, para todas las empresas sin discriminar su actividad. Al respecto, los expertos en marketing identifican algunas prácticas responsables individuales que realizan. Por ejemplo, en los hogares separan los plásticos, los residuos orgánicos y el vidrio, también cuidan el agua y la energía, y hacen uso racional de estos recursos. Adicionalmente, P6 señala que en la organización donde trabaja y es propietario, se separa el aceite y luego se lo entregan a empresas que se encargan de recolectarlo y transformarlo. Así mismo, señala que en las construcciones "proyecto de vivienda que maneja para sus colaboradores" acopian y separan las sobras de ladrillo y tubería, que después recogen las escombreras. Finalmente, los entrevistados coinciden en que, en la actualidad las personas son cada vez más conscientes acerca del cuidado ambiental, pero que, aun así, todavía falta mucho por aprender. 


\subsection{La perspectiva de los consumidores: interés en el consumo de productos y servicios sostenibles, resultado de la implementación de GM en organizaciones de Pereira}

Para el análisis de las encuestas se utiliza la puntuación NPS (Net Promoter Score) con el fin de conocer las medidas mínimas necesarias para solucionar o mitigar las situaciones que están afectando negativamente al medio ambiente. A continuación, se presentan los resultados de las encuestas:

El 77\% de las personas encuestadas es consciente de la problemática ambiental, dentro de las cuales el 18\% tiene una postura pasiva y el 5\% no asume una posición. El NPs permite evidenciar que el 71.28 apunta a una alta preocupación por la problemática ambiental confluyendo como una recomendación del tema.

Frente al conocimiento de medidas para reducir el impacto ambiental, el $49 \%$ de los encuestados tiene una postura pasiva y un $29 \%$ conoce medidas para reducirlo. El NPS de 6.38 da pauta para pensar en implementar estrategias comerciales, gubernamentales e institucionales para dar a conocer las distintas medidas que puedan reducir el impacto ambiental negativo.

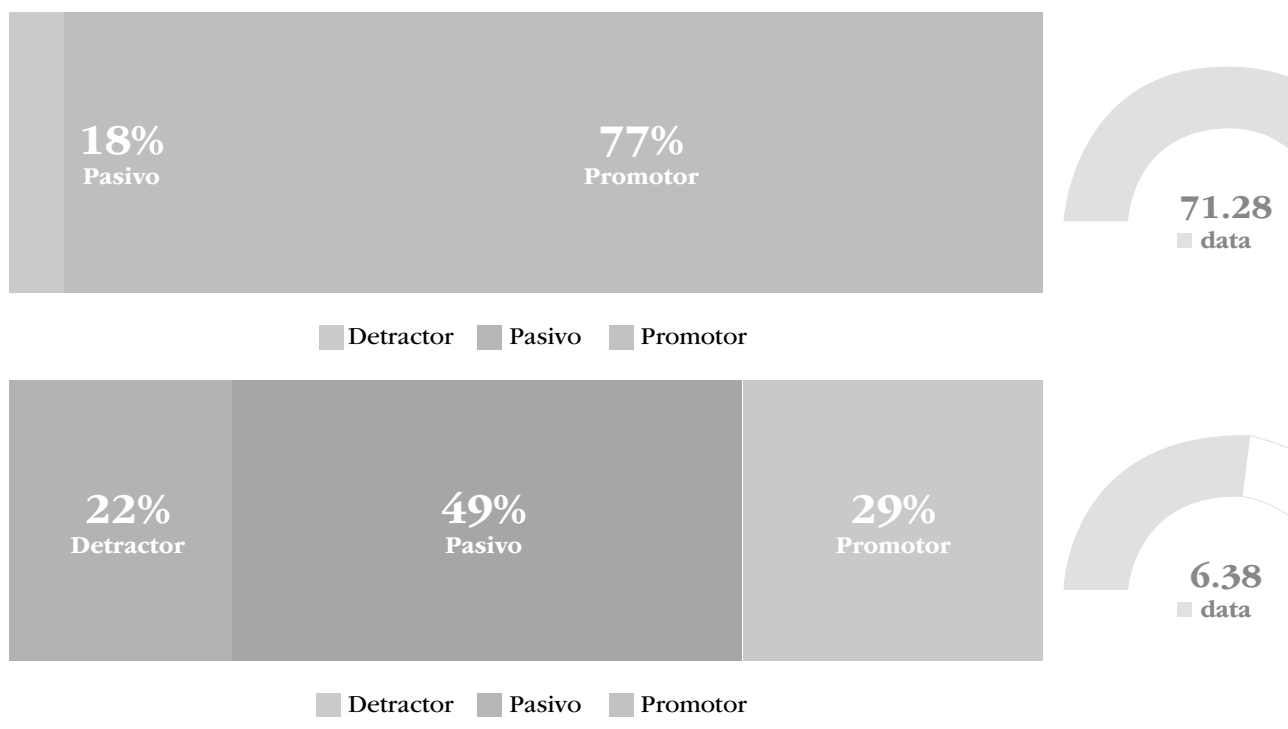

Figura 3. Interés y conocimiento sobre sostenibilidad

Fuente: elaboración propia. 
En cuanto a las prácticas para el cuidado del medio ambiente, un 27\% realiza algunas prácticas efectivas (21\%), a esto se agrega un NPs de 5.32 con lo que se identifica la posibilidad de integrar una comunicación estratégica para fomentarlas.

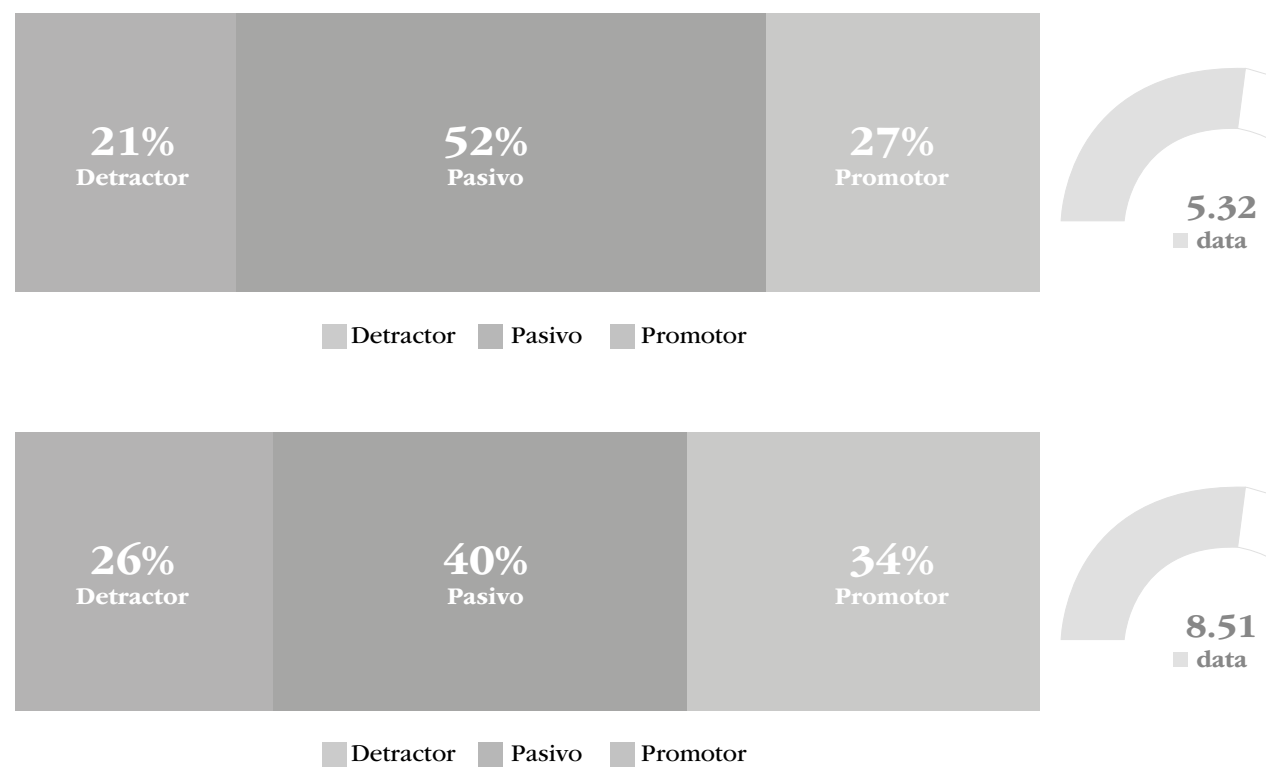

Figura 4. Prácticas y promoción para un consumo amigable con el medio ambiente Fuente: elaboración propia.

En cuanto a hábitos de consumo orientados a cuidar el medio ambiente, un 34\% promueve la adquisición de productos amigables con el medio ambiente y con un NPS de 8.51 revela que ese interés aún no es relevante, sin embargo, se requeriría comparar con comportamientos previos o posteriores. 


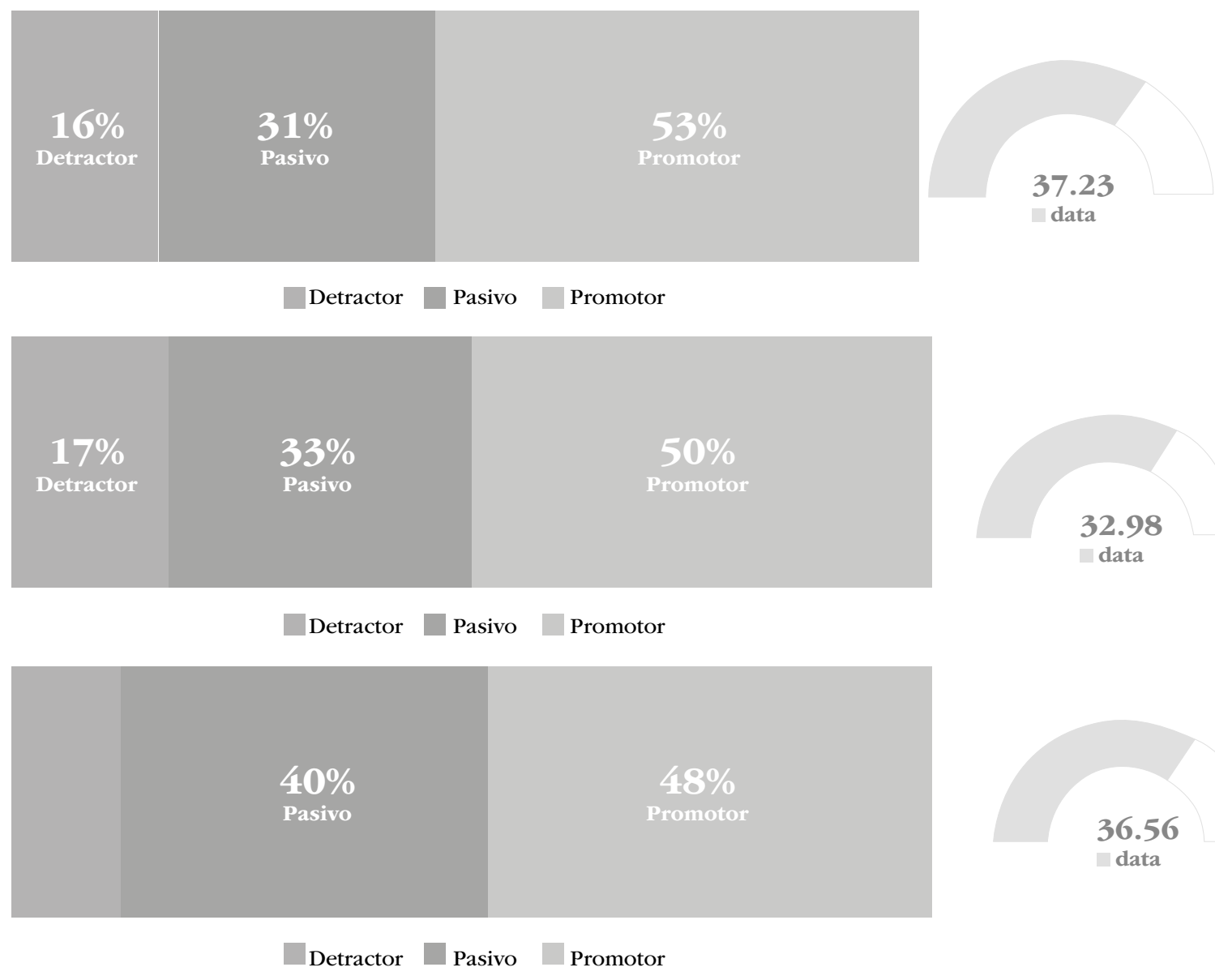

Figura 5. Interés y preferencia por empaques reciclables, compostables y reutilizables Fuente: elaboración propia.

El 53\% de los encuestados prefiere empaques reciclables y el NPs de 37.23 indica que existe una intención de elegir empaques reciclables, por lo que se puede afirmar que se presenta una tendencia al hábito de adquirir productos con dicha característica. Esto también apunta al interés por los empaques de productos compostables: un 50\% lo utiliza, y el NPs de 32.98 indica que hay preferencia por estos. El $48 \%$ de los encuestados muestra interés por empaques reutilizables de los productos, con NPs de 36.56 se muestra cierto interés. Todo lo anterior indica que aún se necesita incentivar en la premisa de reducir, reciclar y reutilizar. 


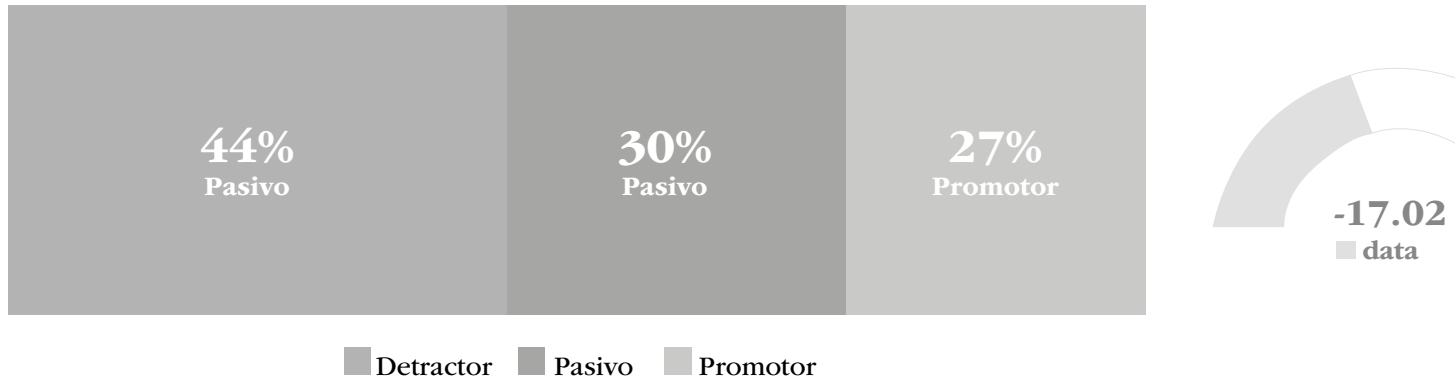

Figura 6. Interés por etiquetas o certificaciones

Fuente: elaboración propia

Un 74\% no muestra interés o es pasivo ante revisar las etiquetas de los productos, pero un $27 \%$ lo considera importante, lo que se relaciona con un NPS de $\mathbf{- 1 7 . 0 2}$ que evidencia que en general no lo están haciendo. Las etiquetas muestran información relevante del producto e integrar estrategias sobre su importancia puede ser pertinente.
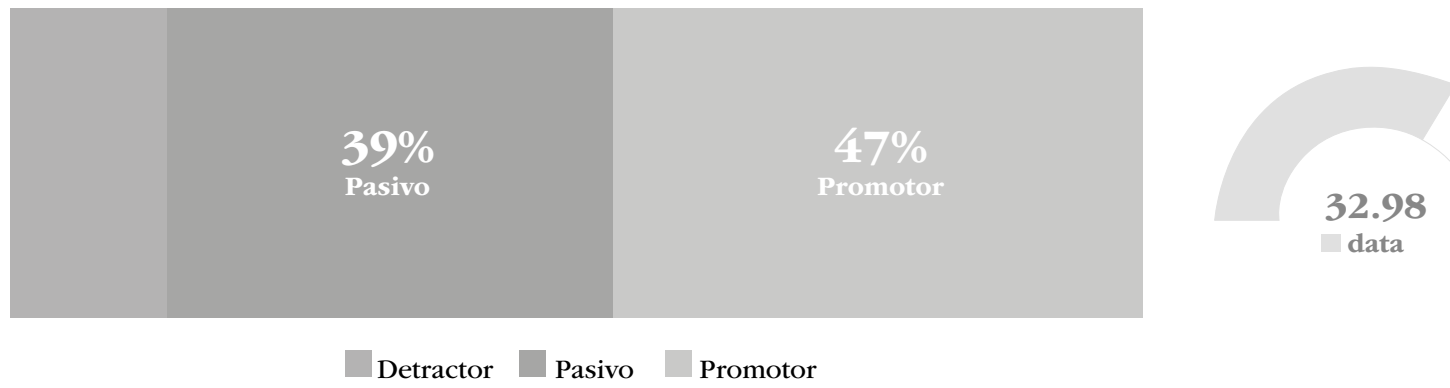

Figura 7. Disposición a pagar por productos amigables con el medio ambiente Fuente: elaboración propia.

El $47 \%$ de los encuestados pagaría más, el 39\% muestra una postura pasiva y el 14\% no estaría en disposición a pagar más por productos que no ocasionen daños al medio ambiente. El NPS 32.98 muestra que hay cierto interés. A tal efecto, orientar con información sobre costo beneficio es un aspecto a tener en cuenta para el GM. 

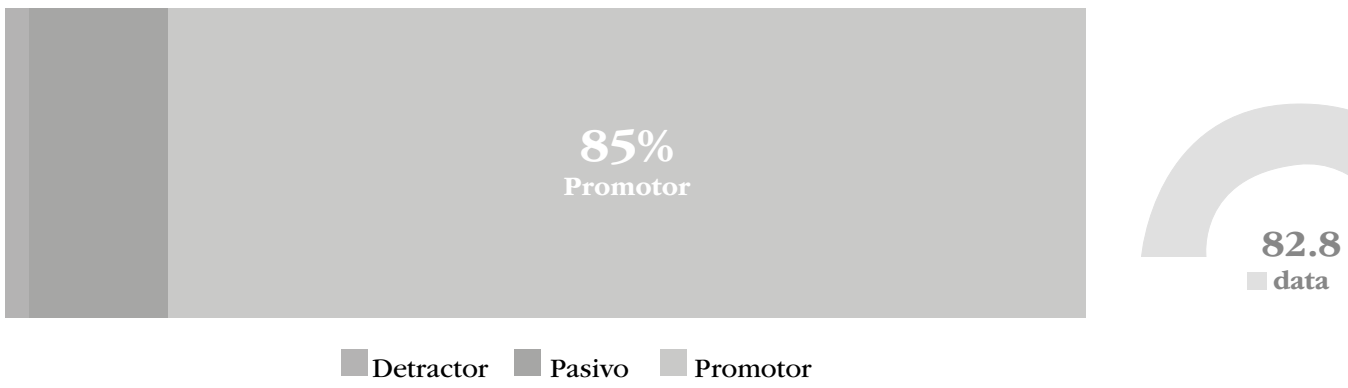

Figura 8. Interés en regulación a operación de organizaciones sobre cuidado medioambiental Fuente: elaboración propia.

El 85\% de los encuestados está de acuerdo con que el gobierno regule la operación de las empresas con el cuidado del medio ambiente, el 15\% muestra una postura pasiva o poco interés. El NPS de 82.8 indica la elevada percepción a favor para que el gobierno vigile la forma de actuar de las empresas en el aspecto ambiental.

E1 56\% apoya movimientos verdes para cuidar el medio ambiente y el NPs de 38.3 revela cierto interés por participar en movimientos para el cuidado ambiental. Esto puede verse como un aspecto que orienta a una creciente tendencia hacia un consumo amigable con el medio ambiente.

Sin embargo, el 63\% no ha participado en eventos relacionados con el cuidado del medio ambiente o tienen una postura pasiva (22\%), en comparación a un 15\% que ha participado en eventos ecológicos, sostenibles o verdes. El NPs de -47.87 muestra un muy bajo interés por eventos de este tipo. 

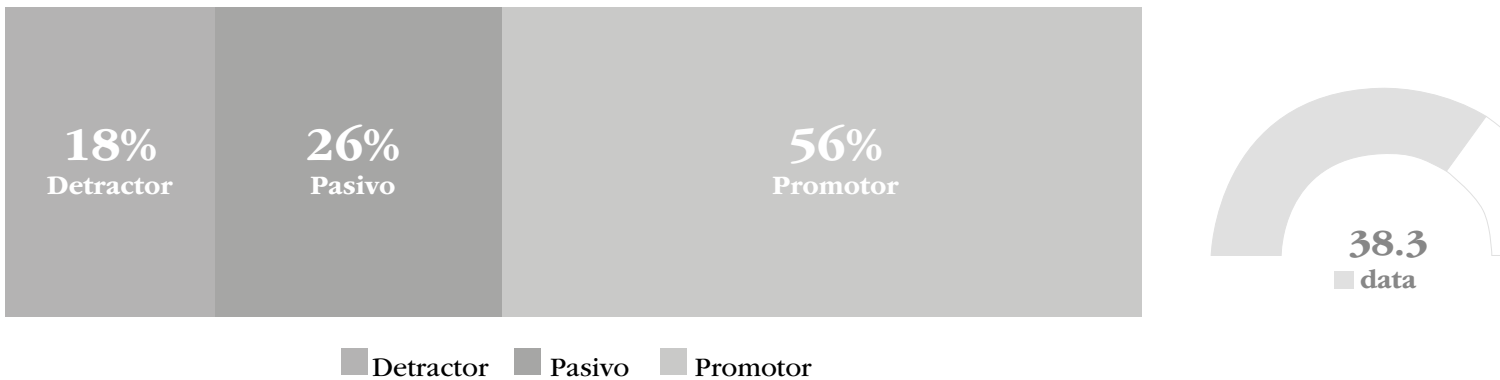

38.3

data

$-47.87$

data

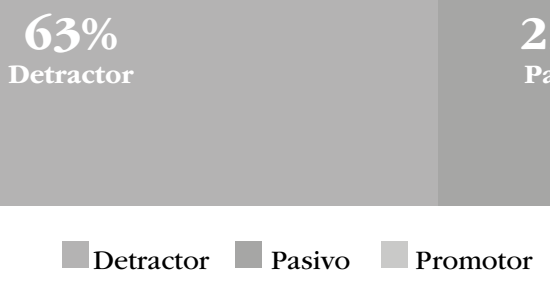

$22 \%$

Pasivo

Figura 9. Interés o participación en movimientos y eventos relacionados con el medio ambiente Fuente: elaboración propia.

En relación con las prácticas de consumo responsables con el medio ambiente, quienes participaron en la encuesta responden que optimizan en recursos como agua y energía (25.10\%), reutilizan, separan y reciclan (24.27\%), eligen materiales naturales $(7.95 \%)$, utilizan el transporte colaborativo o público (7.53\%), todas las nombradas anteriormente $(7.11 \%)$ y otras actividades $(0,84 \%)$. Todas las personas que participaron colaboran de alguna manera con el cuidado y la preservación del medio ambiente en la ciudad donde viven.

\subsection{Bases para orientar la aplicación de green marketing}

Como resultado del estudio, al contrastar lo manifestado por los consumidores con los empresarios y ser socializado con los expertos en marketing, se logró la construcción de un proceso que comprende cuatro etapas y siete eslabones para la conversión de cliente convencional a cliente verde. Se describen y muestran a continuación: 


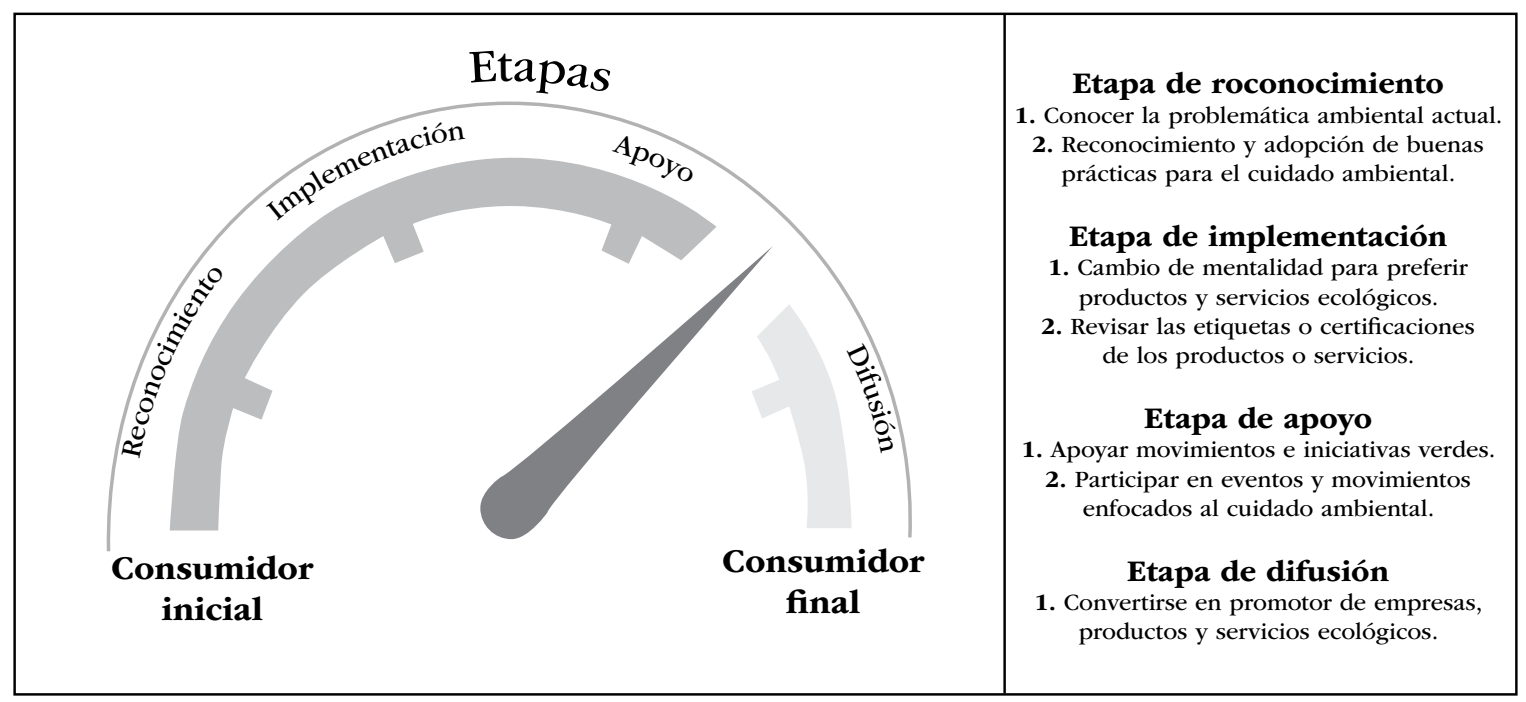

Figura 10. Modelo de consumidores verdes

Fuente: elaboración propia.

Adicionalmente, considerando lo recolectado en las entrevistas, a la comparación de información secundaria con diferentes autores y revisando las regulaciones gubernamentales, se propone un modelo, llamado ADN Verde Empresarial, el cual presenta una sencilla guía para convertir los negocios en negocios verdes. Es necesario mencionar que dicho modelo integra estrategias de diagnóstico ambiental, de producción limpia y de green marketing, este último puede guiarse por las dos primeras para un buen desarrollo de la estrategia. El modelo ADN Verde Empresarial consiste en siete etapas, cada una con distintas líneas de acción. Empieza por un diagnóstico detallado acerca de las buenas prácticas ambientales y sociales que está desarrollando la organización. Con la información recogida, se podrá pasar a un proceso de reestructuración y cambio, convergiendo como etapa transversal y que se irá implementando de acuerdo con los aspectos a mejorar o las oportunidades a aprovechar. En el proceso debe hacerse validación e implementación de acciones con base en la Guía de verificación y evaluación de criterios de Negocios Verdes (MinAmbiente, 2016b), con la que se efectúa un segundo diagnóstico, para corregir y mejorar los requerimientos mínimos para ser un negocio verde. Posteriormente, se procede a la etapa de Certificación de negocio verde, para la cual es necesario postularse mediante formulario en la página del Ministerio de Ambiente y descargar la ficha. Igualmente, se pueden tener las orientaciones que brinda la Alcaldía Mayor de Bogotá, a través de la Ventanilla Distrital de Negocios Verdes de la Secretaría Distrital de Ambiente 
(Alcaldía Mayor de Bogotá, 2013). Al contar con la certificación de Negocios Verdes viene la etapa de Comunicación, en la que es importante divulgar, de manera clara, lo que hizo la organización para obtener dicha certificación. Igualmente, es fundamental mantener informados a los consumidores acerca de las buenas prácticas que se vayan implementando, de manera que, al contribuir con la conservación del medio ambiente, también se posicione a la empresa con campañas en redes sociales, videos, emails, comerciales y radio, entre otros. Finalmente, se contempla una fase de Evaluación y Control, ya que ser un Negocio Verde significa contar con una calificación, que permita evidenciar los aspectos que debe mantener o mejorar. Por último, es indispensable velar por el cumplimiento de las iniciativas verdes siendo muy cuidadosos para no caer en el espejismo del greenwashing.

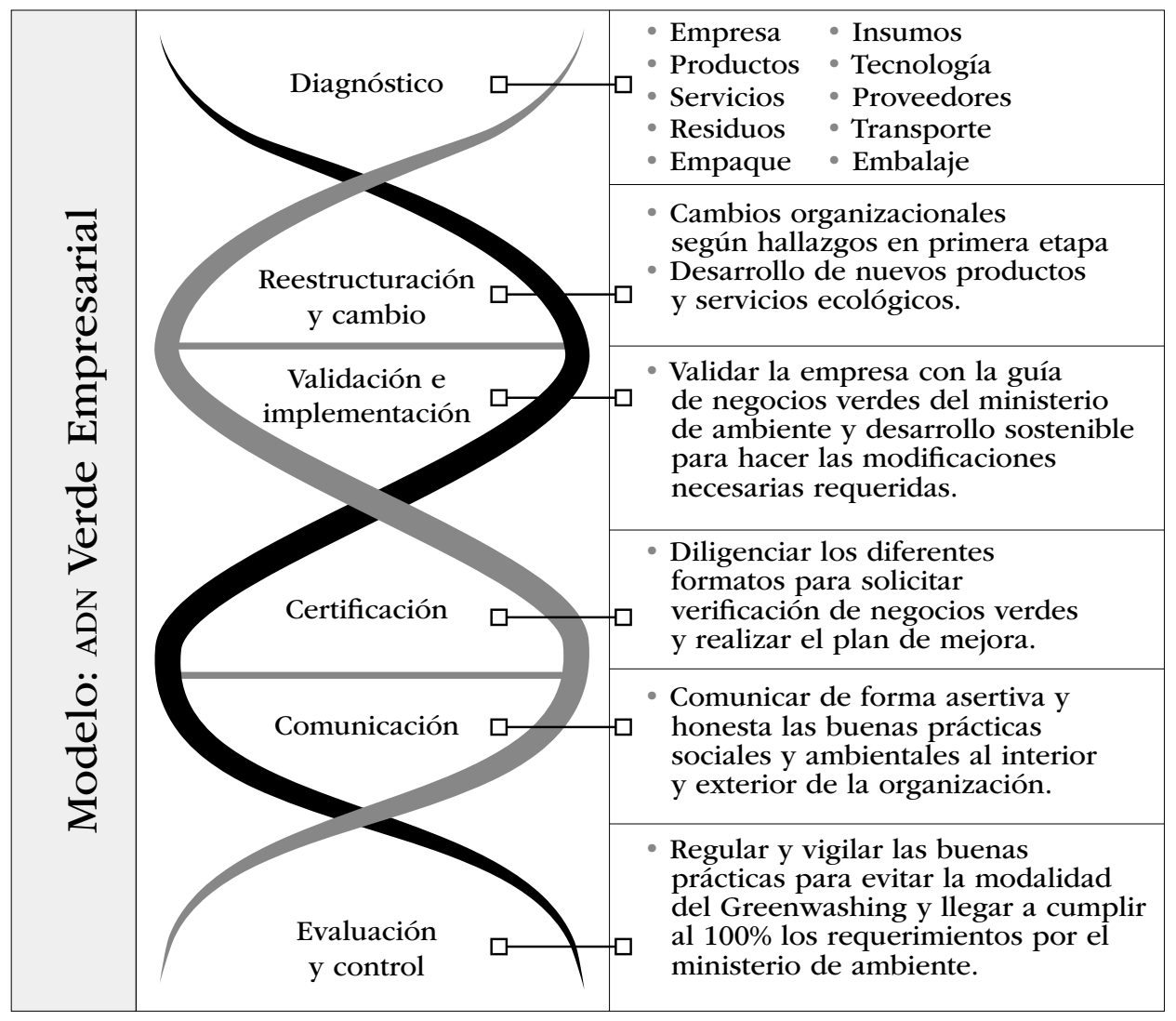

Figura 11. Modelo ADN Verde Empresarial

Fuente: elaboración propia. 


\section{Discusión y conclusiones}

Aplicar el green marketing en las empresas es un asunto que requiere compromiso hacia el cambio desde el nivel gerencial y, por tanto, significa trascender de la política enfocada únicamente en la rentabilidad (El Dief \& Font, 2010). El GM implica implementar políticas y estrategias que permitan la vinculación del personal requerido para ofrecer productos y/o servicios que tengan características sostenibles como apuntan Kotler y Keller (2012), quienes además afirman que a tal efecto el green marketing puede "satisfacer las necesidades del ser humano sin causar mal a futuras generaciones" (p. 633).

En el contexto colombiano, el PND 2018-2022 (Ley 1955 de 2019) da pautas de las acciones que los negocios verdes pueden implementar para mejorar procesos sostenibles de los diferentes recursos o su conservación o hacia la reducción de la contaminación. Así mismo, el Ministerio de Ambiente y Desarrollo Sostenible (MinAmbiente, 2014) tiene establecidos doce lineamientos, desarrollados dentro del Plan Nacional de Negocios Verdes, para que las empresas puedan ser reconocidas como negocios verdes; y define aspectos que permiten a las empresas evolucionar en cuanto a optimización de los factores técnicos, viabilidad económica (aspecto financiero), legal y comercial, mejor percepción de los clientes frente a la empresa y adaptación de modelos sostenibles a factores organizacionales y técnicos. Es importante incluir estrategias para que las empresas conozcan estos lineamientos, dado que, en su mayoría, los conocen poco o los desconocen totalmente.

Las evidencias permiten establecer que hay conocimiento de los problemas ambientales actuales, que son afines a los aspectos evaluados en la matriz de generación de impactos ambientales negativos más recurrentes en el sector empresarial: el agotamiento de recursos naturales, la contaminación de recursos naturales como agua, aire o suelo, la contaminación visual, la afectación a la fauna, entre otros impactos, que se pueden identificar en el Protocolo para el diseño de la matriz de impactos ambientales de la Alcaldía Mayor de Bogotá (2013).

$\mathrm{Al}$ respecto, es vital establecer que las empresas sean muy responsables con la información que comunican, especialmente en lo que corresponde al green marketing con el propósito de no caer en prácticas de lavado verde o greenwashing, que presentan una 
imagen verde pero contradictoria en su naturaleza y que pueden generar desprestigio y sanciones. Por ejemplo, Fuentes (2015) expone el caso de Nordic Nature Shop, que inscribió unas camisetas como verdes para promover la moral verde, pero presentando a la vez otras morales contradictorias.

Para los expertos en marketing que participaron en el grupo focal, no existe un claro mensaje u objetivo de responsabilidad ambiental por algunas empresas, lo que las podría dejar en una delgada línea entre lo que es marketing verde y greenwashing, además, podría influir directamente en lo que aportan los autores Guerreiro \& Pacheco (2021) en los bajos niveles de confianza y los cuestionamientos por parte de los consumidores hacia productos ecológicos

Por otro lado, según las evidencias, y cotejando con Viscarri (2011), los clientes son cada vez más exigentes e informados, lo que impulsa a que las empresas respondan a estas exigencias realizando procesos de reingeniería para ofrecer productos y servicios sostenibles, además, y teniendo en cuenta lo que expresaron los expertos en marketing, se identifica la necesidad de saber comunicar de manera honesta y precisa lo que están haciendo las organizaciones que están apostando por el cambio.

Finalmente, es pertinente señalar que, en Colombia, hay iniciativas locales como las ferias de Colombiatex (Inexmoda, 2021) las cuales se han dirigido a promover la sostenibilidad como eje dentro de sus temáticas, pero es clave que los gobiernos, las institucio-

nes y las empresas también la promuevan y asuman la sostenibilidad con una visión de responsabilidad social, en la que exista la equidad, el trabajo digno, el acceso a salud, la educación, los servicios básicos, la justicia, entre otros.

\section{Referencias}

Alcaldía Mayor de Bogotá. (2013). Instructivo. Diligenciamiento de la Matriz de Identificación de aspectos y valoración de impactos ambientales. Secretaría Distrital de Ambiente. https://www.ambientebogota.gov.co/documents/10184/564058/ Instructivo+para+el+diligenciamiento+de+la+matriz+de+Identificaci\%C3\%B3n+de+aspecto $+\mathrm{y}+$ valoraci $\% \mathrm{C} 3 \% \mathrm{~B} 3 \mathrm{n}+\mathrm{de}+\mathrm{impactos}+$ ambientales. pdf/e $5 \mathrm{f} 7 \mathrm{edbd}-\mathrm{f} 5 \mathrm{~d} 8-4008-8 \mathrm{bda}-\mathrm{pdf} / \mathrm{e} 5 \mathrm{f} 7$ edbd-f5d8-4008-8bda-fb9328d8b98b 
Alqadri Jamal, F. (2021). Dimensions of Consumption Value of Green Repurchase Intention with Green Trust as an Intervening Variable. Marketing Management Studies, 1(3), 163175. https://jkmp.ppj.unp.ac.id/index.php/mms/article/view/103/29

Baquero Garzón, L. Y. (2018). Elaboración de un plan de negocio para la creación de una empresa de ecosistemas urbanos en la ciudad de Bogotá (Tesis de grado). Especialización en Gerencia para el desarrollo organizacional, Universidad de Cundinamarca. http://repositorio.ucundinamarca.edu.co/bitstream/handle/20.500.12558/1407/ELABORACION\%20 DE\%20UN\%20PLAN\%20DE\%20NEGOCIO\%20PARA\%20LA\%20CREACION\%20DE\%20 UNA\%20EMPRESA\%20DE\%20ESOSITEMAS\%20URBANOS\%20EN\%20LA\%20CIU.pdf?sequence $=1 \&$ isAllowed $=\mathrm{y}$

Bathia, M., \& Jain, A. (2013). Green marketing: A study of consumer perception and preferences in India. Electronic Green Journal, (36). https://doi.org/10.5070/G313618392

Bowen, F., \& Aragon-Correa, J. A. (2014). Greenwashing in Corporate Environmentalism Research and Practice: The Importance of What We Say and Do. Organization $\mathcal{E}$ Environment, 27(2), 107-112. https://doi.org/10.1177/1086026614537078

Cardona Arbeláez, D. (2018). Marketing Green y el avance tecnológico como apuesta de innovación para el desarrollo de las estrategias de marketing. Revista Espacios, 39(26), 2-12. https://www.revistaespacios.com/a18v39n26/a18v39n26p02.pdf

Castellano, S., \& Urdaneta, J. A. (2015). Estrategias de marketing verde utilizadas por empresas a nivel mundial. Telos, 17(3), 476-494. https://www.redalyc.org/pdf/993/99342682007.pdf

Cervera Taulet, A. C., Schlesinger Díaz, M. W., Iniesta, M. A., \& Sánchez-Fernández, R. (2010). Image, Satisfaction and Identification as antecedents of graduate loyalty. En L. Matei, \& T. Dinu (Eds.), Regulation and Best Practices in Public and Nonprofit Marketing (pp. 151-161). Editura Economică. https://core.ac.uk/download/pdf/211595843.pdf\#page=152

Dangelico, R. M., \& Pontrandolfo, P. (2010). From green product definitions and classifications to the Green Option Matrix.Journal of Cleaner Production, 18(16-17), 1608-1628. https:// doi.org/10.1016/j.jclepro.2010.07.007

Das, S. M., Dash, B. M., \& Padhy, P. C. (2012). Green Marketing Strategies for Sustainable Business Growth.Journal of Business Management \& Social Sciences Research, 1(1), 82-87. http://citeseerx.ist.psu.edu/viewdoc/download?doi=10.1.1.829.5447\&rep=rep1\&type=pdf

Decreto 280 de 2015. Por el cual se crea la Comisión Interinstitucional de Alto Nivel para el alistamiento y la efectiva implementación de la Agenda de Desarrollo Post 2015 y sus Objetivos de Desarrollo Sostenible (oDs). Diario Oficial N. ${ }^{\circ} 49.42918$ de febrero de 2015. http://www.suin-juriscol.gov.co/viewDocument.asp?ruta=Decretos/30019753 
Dias, R. (2008). Marketing ecológico y turismo. Estudios y Perspectivas en Turismo, 17(2), 144-155. https://www.estudiosenturismo.com.ar/search/PDF/v17n1y2a7.pdf

Domínguez Gual, M. C. (2015). La contaminación ambiental, un tema con compromiso social. Producción+limpia, 10(1), 9-21. http://www.scielo.org.co/scielo.php?script=sci_arttext\&pid=S1909-04552015000100001

El Dief, M., \& Font, X. (2010). The determinants of hotels' marketing managers' green marketing behaviour. Journal of Sustainable Tourism, 18(2), 157-174. https://doi. org/10.1080/09669580903464232

Elkington, J., \& Hailes, J. (1988). The Green Consumer Guide: From Shampoo to Champagne. Victor Gollancz.

Fuentes, C. (2015). How green marketing works: Practices, materialities, and images. Scandinavian Journal of Management, 31(2), 192-205. https://doi.org/10.1016/j. scaman.2014.11.004

Guerreiro, J., \& Pacheco, M. (2021). How green trust, consumer brand engagement and green word-of-mouth mediate purchasing intentions. Sustainability, 13(14), 1-13. https://doi. org/10.3390/su13147877

Hallama, M., Montlló Ribo, M., Rofas Tudela, S., \& Ciutat Vendrell, G. (2011, julio-septiembre). El fenómeno del greenwashing y su impacto sobre los consumidores: propuesta metodológica para su evaluación. Aposta, (50), 4-38. https://www.redalyc.org/pdf/4959/495950246004.pdf

Inexmoda. (2021). Ruta de la Sostenibilidad y Bioseguridad. https://ferias.inexmoda.org.co/ ruta-de-la-sostenibilidad/

Jenkin, G., Madhavi, N., Signal, L., \& Bowers, S. (2014). A systematic review of persuasive marketing techniques to promote food to children on television. Obesity Reviews, 15(4), 281-293. https://doi.org/10.1111/obr.12141

Johnstone, M. -L., \& Hooper, S. (2016). Social influence and green consumption behaviour: a need for greater government involvement. Journal of Marketing Management, 32(9-10), 827-855. https://doi.org/10.1080/0267257X.2016.1189955

Kharde, S. D. (2016). Indian Scenario of Green Marketing. Journal for Research, 2(1), 37-41. https://www.academia.edu/25823165/Indian_Scenario_of_Green_Marketing

Kotler, P., \& Keller, K. (2012). Dirección de marketing (14. ${ }^{a}$ ed.). Pearson.

Kotler, P., \& Keller, K. (2016). Dirección de marketing (15. ${ }^{\mathrm{a}}$ ed.). Pearson.

Lara Domínguez, P. A. (2015). El impacto del ruido ambiental en los pacientes de una unidad de cuidados intensivos ¿Es posible un cambio? (Tesis doctoral). Universidad de Málaga. https://core.ac.uk/download/pdf/75996988.pdf 
Leff, E. (2018). La complejidad ambiental. Siglo XXI.

Ley 1955 de 2019. Por el cual se expide el Plan Nacional de Desarrollo 2018-2022. "Pacto por Colombia, Pacto por la Equidad”. Diario oficial N. ${ }^{\circ}$ 50964, del 25 de mayo de 2019. http:// www.suin-juriscol.gov.co/viewDocument.asp?ruta=Leyes/30036488

Ley 373 de 1997. Por la cual se establece el programa para el uso eficiente y ahorro del agua. Diario Oficial N. 43.058 de 11 de junio de 1997. https://www.minsalud.gov.co/sites/rid/ Lists/BibliotecaDigital/RIDE/INEC/IGUB/Ley-373-de-1997.pdf

Ley 697 de 2001. Por cual se fomenta el uso racional y eficiente de la energía, se promueve la utilización de energías alternativas y se dictan otras disposiciones. Diario Oficial $\mathrm{N}^{\circ}{ }^{\circ}$ 44.573, de 05 de octubre de 2001. http://www.secretariasenado.gov.co/senado/basedoc/ ley_0697_2001.html

Ley 9 de 1979. Por la cual se dictan Medidas Sanitarias. Diario Oficial N. ${ }^{\circ} 35308$, del 16 de julio de 1979. https://www.minsalud.gov.co/Normatividad_Nuevo/LEY\%200009\%20DE\%20 1979.pdf

Luttropp, C., \& Lagerstedt, J. (2006). EcoDesign and the ten golden rules: generic advicefor merging environmental aspects into product development. Journal of Cleaner Production, 14(15/16), 1396-1408. https://doi.org/10.1016/j.jclepro.2005.11.022

Ministerio de Ambiente y Desarrollo Sostenible, MinAmbiente (2014). Plan Nacional de Negocios Verdes. https://isfcolombia.uniandes.edu.co/images/20152/Plan_Nacional_ngocios_verdes.pdf

Ministerio de ambiente y desarrollo sostenible, MinAmbiente. (2016a) Informe de gestión 2015. https://www.minambiente.gov.co/wp-content/uploads/2021/10/Informe_de_ Gestio\%CC\%81n_MINAMBIENTE_2015.pdf

Ministerio de Ambiente y Desarrollo Sostenible, MinAmbiente. (2016b). Guía de verificación $y$ evaluación de criterios de Negocios Verdes. https://www.minambiente.gov.co/negocios-verdes/criterios-para-identificar-los-negocios-verdes/

Navarro, J. V. (1971). La manipulación publicitaria: una antropología del consumo. Dopesa.

Northen, G. (2011). Greenwashing the organic label: abusive Green Marketing in an increasingly eco-friendly marketplace. Journal of Food Law \& Policy, 7(1), 101-134. https://scholarworks.uark.edu/cgi/viewcontent.cgi?article=1133\&context=jflp

ONu. (2015). Objetivos de Desarrollo Sostenible. https://www.un.org/sustainabledevelopment/ es/objetivos-de-desarrollo-sostenible/

Peattie, K. (1995). Environmental Marketing Management: Meeting the Green Challenge. Pearson. 
Peñalosa Otero, M. E., \& López Celis, D. M. (2018, enero-junio). El estereotipo de los colombianos frente al consumo socialmente responsable. Pensamiento y Gestión, (44), 243-260. https://rcientificas.uninorte.edu.co/index.php/pensamiento/article/view/10384

PNUD, BID, Gobierno de Colombia. (2015). Agenda 2030. Transformando Colombia. https://www.co.undp.org/content/colombia/es/home/library/environment_energy/agenda-2030-transformando-colombia.html

Polonsky, M., \& Rosenberger, P. (2001, September-October). Reevaluating Green marketing: A Strategic Approach. Business Horizons, 44(5), 21-30. https://doi.org/10.1016/S00076813(01)80057-4

Robèrt, K. -H. (1995). The Natural Step: A Framework for Achieving Sustainability in Our Organizations. Pegasus Communications.

Roy, R., Wield, D., Gardiner, J. P., \& Potter, S. (1996). Innovative Product Development. The Open University.

Salas Canales, H. (2018, enero-junio). El greenwashing y su repercusión en la ética empresarial. Neumann Business Review, 4(1), 28-43. https://doi.org/10.22451/3002.nbr2018. vol4.1.10018

Santamaría de Zulueta, C. (2018). El greenwashing: práctica recurrente entre las grandes multinacionales (Tesis de grado). Comillas Universidad Pontificia. https://repositorio. comillas.edu/xmlui/handle/11531/23768

Schmidheiny, S. (1992). Changing Course: A Global Business Perspective on Development and the Environment. MIT Press.

Sharma, A., \& Iyer, G. R. (2012). Resource-constrained product development: Implications for green marketing and green supply chains. Industrial Marketing Management, 41(4), 599-608. https://doi.org/10.1016/j.indmarman.2012.04.007

Shrikanth, R., \& Raju, D. S. N. (2012). Contemporary Green Marketing - Brief Reference to Indian Scenario. International Journal of Social Sciences \& Interdisciplinary Research, 1(1), 26-39. https://www.academia.edu/6875687/international_journal_of_social_sciences_and_interdisciplinary_research_contemporary_green_marketing_brief_reference_to_indian_scenario

Simon, F. L. (1992). Marketing green products in the triad. Columbia Journal of World Business, $27(3-4), 268-285$.

Tommasino, H., Foladori, G., \& Taks, J. (2005). La crisis ambiental contemporánea. En G. Foladori, \& N. Pierri (Coords.) ¿Sustentabilidad? Desacuerdos sobre el desarrollo sustentable (pp. 9-26). Cámara de Diputados; Universidad Autónoma de Zacatecas; Porrúa. https:// 
diversidadlocal.files.wordpress.com/2012/09/desacuerdos-sobre-el-desarrollo-sustentable.pdf

Viscarri, J. (2011). Modelo de creación de valor para el cliente. XV Congreso Internacional de Contaduría, Administración e Informática (pp. 1-17). Universidad Politécnica de Cataluña. http://upcommons.upc.edu/handle/2117/16640

Westbrook, G., \& Angus, A. (s. f.). 10 principales tendencias globales de consumo para 2021 [Informe]. Euromonitor Internacional. https://www.granotec.com/noticias-granotec/194-las-10-principales-tendencias-globales-de-consumo-para-2021

Willums, J. -O (1998) The sustainable business challenge, A briefing for tomorrows business leaders. Greenleaf publishing.

Yazdanifard, R., \& Mercy, I. E. (2011). The impact of Green Marketing on Customer satisfaction and Environmental safety. International Conference on Computer Communication and Management, 5, 637-641.https://www.researchgate.net/publication/268502673_The_impact_of_Green_Marketing_on_Customer_satisfaction_and_Environmental_safety 